\title{
The unique research on the informal ties and social networks in East Asia: Diverse perspectives and new research agenda
}

\author{
Peter Ping $\mathrm{Li}^{1,2,3} \cdot \mathrm{En} \mathrm{Xie}^{4}$ \\ Published online: 19 March 2019 \\ (C) Springer Science+Business Media, LLC, part of Springer Nature 2019
}

It is our pleasure to introduce the Special Issue of the Asia Pacific Journal Management with the focus on the theme of Informal Social Networks in East Asia. This introduction is organized into three parts, with the first part covering the background and review process of the Special Issue; the second part covering the specific contents of the nine articles included in the Special Issue, and the third part covering the critical implications of the Special Issue.

\section{The background and review process}

It is generally assumed that informal institutions, shaped by various history and cultural forces, play a strong role wherever formal institutions are absent or ineffective (North, 1990; Peng, 2003). However, an emerging view is that informal institutions can remain strong or even reemerge as increasingly relevant after formal institutions have been firmly established (Horak \& Klein, 2016; Li, 1998, 2007a, 2007b, 2008). For instance, unanswered as the focus of one ongoing debate is the question if guanxi or other types of informal ties and networks will persist (if it is culturally driven) or diminish (if it is institutionally driven) with the further development of the Chinese economy and the establishment of formal institutions in China (cf. Guthrie, 1998; Li, 2007a; Nee, 1992; Peng, 2003; Yang, 1994). This could be the reason why the research on informal ties and networks has been growing rapidly in the management literature in more recent years, especially in the context of East Asia as compared to that in the West (e.g., Begley, Khatri,

\section{Peter Ping Li}

ppl.egb@cbs.dk

1 University of Nottingham Ningbo China, Ningbo, China

2 Center for Creative Leadership, Shanghai, China

3 Copenhagen Business School, Copenhagen, Denmark

4 Tongji University, Shanghai, China 
\& Tsang, 2010; Bstieler \& Hemmert, 2008; Burt, 2019; Hamaguchi, 1985; Horak \& Taube, 2016; Lee, 2000; Lew, 2013; Li, 1998, 2007a).

Further, despite the large body of research on guanxi and a recent growth of research on the informal ties and networks in South Korea, there is little consensus on the unique nature and also the core features of guanxi and other forms of informal ties and networks in East Asia as compared to the Western notions of social capital and social network (Horak \& Klein, 2016; Li, 2007a, 2007b). For instance, so far most scholars assume that the debates exist under the umbrella notion of social capital or social tie as a universal construct. However, some scholars have started questioning if the informal ties and networks in the context of East Asia fit to the notion of social capital because it is framed from the Western perspective for the special type of informal ties and networks prevailing in the West, thus not necessary the same as in the East. Still unanswered is the critical question if the informal ties and networks in the East should be conceptualized as the Eastern version of social capital or as a unique category of their own (e.g., Burt, 2019; Horak \& Taube, 2016; Li, 2007a).

To advance the research on the uniqueness of informal ties and networks in the context of East Asia, the intra-regional comparative perspective is interesting as a new research agenda beyond the current narrow focus on the Chinese informal ties and networks (i.e., guanxi) (see Chen, Chen, \& Huang, 2013; Luo, Huang, \& Wang, 2012, for reviews). It is surprising that the characters and roles of informal ties and networks in other countries of East Asia than China have been largely ignored. There appear to be both fundamental similarities and distinctions between the informal ties and networks in East Asia as a region with many shared cultural traditions. This is especially true for those among China, Japan and South Korea as the top three economies in this region.

We posit that developing a theory of informal ties and networks in East Asia confined to guanxi alone is insufficient because there exist other forms or types of informal ties and networks across East Asia, so we need to expand the research to other major countries in East Asia, especially Japan and South Korea. There are two core reasons for such an expansion of research focus. First, current literature often assumes the Chinese informal ties and networks to be equal or similar to their counterparts in other East Asian countries, but this may not be the case even though the three countries share the same traditional notion of informal ties and networks in terms of "renmai" in Chinese, "jin myaku" in Japanese, and "inmaek" in Korean, all being based on the same Chinese characters of “人脉”, the three forms or types of informal ties and networks bear subtle differences in basic characters and roles (Horak \& Klein, 2016). Located in the same region but at different levels of economic and social development, highly interesting research questions can emerge from the comparability of cultural and historical similarities and distinctions between the three countries in East Asia. For instance, a closer look reveals that the Chinese informal ties and networks seem to be comparatively more open to outsiders and also more flexible in their operation than the Korean ones, while the Japanese ones may be closer to the Korean type than the Chinese type (e.g., Hamaguchi, 1985; Horak \& Taube, 2016; Lew, 2013; Li, 2007a).

Second, the persistence of informal ties and networks in Japan and South Korea can shed light on if informal ties and networks would persist or diminish over time. For instance, informal ties and networks in Korea (yongo network or "inmaek"), despite the rapid growth of the Korean economy since the 1960s and its economic importance 
today, the influence of yongo network ("inmaek") remains tremendous, but it has received much less scholarly attention compared to China (Yee, 2000). Recently, Lew (2013) argued that yongo can be regarded the 'missing link' in explaining Korea's rapid economic growth, next to the well known conventional themes, such as strong state, an export oriented economic policy and the role of the Chaebol. Though Japanese institutions, formal as well as informal ones, have been studied since the early 1980s, we know surprisingly little about the character and role of informal ties and networks in the past and present situation in Japan (see Hamaguchi, 1985 for a rare exception; also see Gilbert, 2003; Suzuki, 1989). In this sense, the expanded research on the informal ties and networks in Japan and South Korea can shed light on the debate over if guanxi networks will persist or disappear as China, simply because the Korean informal ties and networks seem to persist or even intensify, despite its achieved status of a developed economy and a stable democracy with wellestablished and functional formal institutions (Bstieler \& Hemmert, 2008; Lee, 2000; Yang, 2006), similar to the case of Japanese ones (Hamaguchi, 1985). This appears to challenge the conventional assumption that once formal institutions mature, the role of informal institutions tend to decline (Guthrie, 1998; Nee, 1992; Peng, 2003). In this sense, a comparative research on various types of informal ties and networks in China, Japan and South Korea will shed light on the above debate, especially the effect of the interaction between formal and informal institutions.

The above-mentioned interaction between informal and formal institutions provides the unique opportunity to reveal the salient need to examine informal ties and networks in light of their interaction with formal counterparts, and more importantly the increasingly recognized need for a proper balance between formal and informal elements (Horak \& Restel, 2016; Lin et al., 2015; Li, 2007b). An emerging trend is to frame opposite elements as duality or paradox in line with the unique Chinese perspective of yin-yang balancing (阴阳平衡 in Chinese), where opposite elements in a pair are not only partially conflicting (相生相克衡 in Chinese), but also partially complementary (Li, 1998, 2016). Applying this perspective to the study of informal-formal balance is relevant and helpful with major implications for future research.

In particular, this Special Issue has been specifically designed to shed light on the ongoing debates by aiming to address the following three fundamental questions:

- What are the major similarities and distinctions between the informal social networks in East Asia in general, and China, Japan, and South Korea in particular?

- What are the similarities and distinctions between the informal social networks in East Asia and the concept of social capital as conceptualized in the West?

- Would informal social networks persist or disappear when formal institutions are more established in the later stages of societal development?

Given the special focus on the indigenous topic of informal networks in the unique context of East Asia, our Special Issue has attracted a decent number of submissions before and on the due date of September 1, 2016, a total of third-one submissions. However, some of those submissions were desk rejected (a set of twelve submissions with a desk-rejection rate of close to $40 \%$ ) simply because they did not fit the focus of this Special Issue, such as not focusing on informal ties or networks, or not in the 
context of East Asia, thus resulting in a set of nineteen submissions being sent out for review. Finally, nine submissions have been finally accepted on time for publication in the Special Issue (an acceptance rate of less than 30\%). There are still three submissions under review, but we cannot wait for them, so they will be treated as submissions to regular issues.

The geographical scope of all the submissions to the Special Issue covers primarily China and South Korea, without a single submission from Japan. Out of the nine articles in the Special Issue, two articles cover South Korea; five articles cover China; one article compares China and South Korea, and one article compares distinctive networks between the East and the West.

For this Special Issue, a two-day workshop for paper development was hosted by Xi'an Jiaotong Universeity, China, in June 2017, for the exchange of ideas about how to enhance the submitted papers as well as ensure a thematic coherence among the contributed papers. In our original plan, we intended to have this Special Issue published at the end of 2017, but we have encountered various challenges so that we now only publish in the early part of 2019.

In the next three sections, we will first introduce the specific contents of the published articles in this Special Issue, and then discuss the major implications of these articles for future research in the domain of informal networks in the specific context of East Asia in particular and the general context of emerging world characterized by volatility, uncertainty, complexity and ambiguity (VUCA).

\section{The specific contents of the published articles}

The sequential order in the set of nine accepted articles in the Special Issue is organized in terms of their scopes and focuses, and the whole set can be divided into three subsets.

The first sub-set consists of two articles that are concerned with the comparative study of informal ties and networks between distinctive cultures, primarily between the cultural clusters of the East and the West as well as secondarily between the specific cultures within the region of East Asia. The first article is a meta-analysis of diverse structural features of network (such as network centrality and structural hole) across distinctive cultures (such as loose or tight cultures and individualistic or collectivist cultures), especially between the East and the West. The second article is conceptual in nature as a comparative study on distinctive informal ties and networks between the East and the West as well as between the three major countries within East Asia, i.e., China, South Korea, and Japan.

The second sub-set consists of two articles that are exclusively concerned with the informal ties and networks in South Korea. The first article is an exploratory study that empirically examines the relevance of interpersonal ties and inter-organizational tie strength to interaction quality and outcomes of research collaborations in South Korea. The second article is conceptual in nature with a special focus on the emotional or affective features of informal ties and networks in contrast to the conventional or dominant focus on the cognitive elements.

The third and last sub-set consists of five articles that are exclusively concerned with the informal ties and networks in China. Among the five articles focusing on China, a 
special order is deliberately selected. The first article in this sub-set is concerned with the unique mentoring relationship in China as compared with the conventional mentoring relationship in the West. Further, the second and third article are concerned with inter-firm interaction in the sector of manufacturing in China, with the first about the roles and functions of informal ties and networks in the specific context of innovation among manufacturing firms in China, and the second about the roles and functions of informal ties and networks in the special context of international expansion among manufacturing firms in China. Finally, the last two articles are concerned with firm-level and household-level activities in the specific sector of finance services in China, with the first about the roles and functions of informal ties and networks in the special context of syndicated investment among venture capital firms, and the other about the roles and functions of informal ties and networks in the special context of informal borrowing and lending among households.

More specifically, the contents of the above nine articles are introduced in more detail next.

Entitled "A tale of two cultures: Social networks and competitive advantage", and written by Haifeng Wang, Longwei Tian, and Yuan Li, the first article focuses on how firm networks function in different cultures, especially concerning the distinctive cultural clusters of the East and the West. This study applies the method of metaanalysis to examining the special impacts of tightness-looseness and individualistcollectivist cultures on the links between network centrality, structural hole and competitive advantage. Based on a sample from 74 studies encompassing 30,930 samples, this study has found that network centrality has a stronger positive impact on competitive advantage than structural hole. In addition, the findings indicate that the positive impacts of both network centrality and structural hole on competitive advantage are higher in loose cultures than in tight cultures. Further, this study has also found that the positive impacts of both network centrality and structural hole on competitive advantage are higher in individualist cultures than in collectivist cultures.

Entitled "Two not of a kind: Social network theory and informal social networks in East Asia", and written by Sven Horak, Markus Taube, Inju Yang and Katja Restel, the second article conceptually analyzes the core assumptions and ideals of social network characteristics in the East and the West. By using a conceptual framework derived from the literature and consisting of key antecedents to social networks, this study has found the differences between the conventional assumptions about the features of social network in the West and those in East Asia. Moreover, this study has also found remarkable intra-regional differences. Among these, and contrary to common beliefs about social networks, this study has found that weak ties are neither truly effective nor preferably used in East Asia, where strong ties are both more preferred and more powerful. Further, social ties tend to be rather sentimental, and social networks tend to be rather closed. Also, depending on the nature of social network, bridging neither works nor is intended in East Asia. This study recommends further studies explicitly taking local context into account in order to refine or reframe extant knowledge on social networks.

Entitled "The relevance of interpersonal ties and inter-organizational tie strength for outcomes of research collaborations in South Korea, and written by Martin Hemmert, the third article focuses on interpersonal ties that have long been recognized as relevant not only for interaction between individuals, but also for knowledge transfer and other 
important outcomes of business activities. This applies in particular to East Asian countries such as South Korea where informal social networks are widely prevalent in business and society. However, less is known about their role in inter-organizational collaboration efforts, such as research collaborations. This exploratory study empirically examines the relevance of inter-personal ties and inter-organizational tie for interaction quality and outcomes of research collaborations in South Korea. Two types of research collaborations are studied: new product development (NPD) collaborations between companies and university-industry research collaborations (UICs). Interpersonal ties are found in a majority of both types of research collaboration being studied. However, whereas the strength of inter-organizational tie is positively related to outcomes of these research collaborations, the strength of interpersonal ties is not. In this sense, managers should not primarily rely on interpersonal ties for partner selection and the management of research collaborations.

Entitled "Emotions, indigenous affective ties, and social network theory-The case of South Korea", and written by Inju Yang and Sven Horak, the fourth article conceptually explores the structural and emotional aspects of informal social networks in South Korea by examining the indigenous concepts of jeong, woori, inmaek, and yongo in relation to the theories of social networks, social capital, and social exchange. This study suggests extending extant knowledge of the latter by pursuing the geocentric integration of Eastern and Western schools of thought on crucial elements of social networks, chiefly by focusing on affective characteristics compared to the conventional and dominant focus on cognitive characteristics in the West. Moreover, this study highlights the dualistic nature of informal ties by adapting the notions of yin-yang (阴阳 in Chinese) and zhongyong (中庸 in Chinese). Based on the results of the above analysis, this study suggests explicitly incorporating interpersonal affection or emotion as the salient constituting element of social network development and cohesion.

Entitled "Understanding mentoring relationships in China: Towards a Confucian model", and written by Abby Jingzi Zhou, Émilie Lapointe and Steven Shijin Zhou, the fifth article focuses on the unique version of mentoring relationship in China. Most mentoring research conducted in Asia is based on theories developed in the Western world and quantitatively tests mentoring-related hypotheses rather than attempting to gain an in-depth understanding of mentoring in the Asian context. This study contributes by fillinging the above gaps in the literature by examining mentoring relationships in China. In-depth interviews were conducted among mentors and mentees to explore their experience of the mentoring relationship in the context of China. The findings highlight commonalities with mainstream mentoring research as well as several distinctive features. The findings are integrated in a contextualized model of mentoring that echoes the pervasive influence of Confucianism in China. Other theoretical implications and future research directions are discussed.

Entitled "More ties the merrier? Different social ties and firm innovation performance," and written by Jianghua Zhou, Rui Wu, and Jizhen Li, the sixth article focuses on the topic of inter-organizational relationships. Viewed as a special form of social ties, inter-organizational relationships have been examined as a key source of firm innovation. While scholars highlight the importance of social ties, much less is known regarding the relationships among different types of ties. This study first examines the individual effects of three types of social ties on firm innovation performance: political, business, and university ties. This study then analyzes the joint 
effects of these ties. This study argues that political ties strengthen the positive effects of business and university ties on innovation. Built upon the empirical evidence for the above arguments with a recent sample of Chinese firms, this study contributes to a better understanding of innovation implications of external ties.

Entitled "Does guanxi matter in the foreign expansion of Chinese manufacturing firms? The mediator role of linking and leveraging", and written by Jian Du and Chao Zhou, the seventh article explores how two types of guanxi (guanxi with the government, guanxi with business partners) shape the international expansion of firms from emerging countries. We propose that both guanxi with the government and guanxi with business partners are important in the internationalization effort and that their effects on firms' international expansion are channeled through linking and leveraging capabilities, respectively. The data from a sample of 112 Chinese firms in the manufacturing sector provide support for the positive effects of guanxi on capabilities and of capabilities on internationalization. Specifically, this study demonstrates support for the mediator role of linking capability in the relationship between guanxi with the government and international expansion. In addition, the mediating effect of leveraging capability in the relationship between guanxi with business partners and firms' internationalization is confirmed in this study.

Entitled "Syndication through social embeddedness: A comparison of foreign, private and state-owned venture capital (VC) firms", and written by Jar-Der Luo, Ke Rong, Kunhao Yang, Rong Guo and Ya-Qi Zou, the eighth article explores the different syndication behavior in various types of Chinese venture capitals (VC), in particular it focuses on foreign, private-owned and state-owned VC firms and these firms' behavior when faced with institutional uncertainties. Mixed methods data analysis was conducted using the Simuton database of 1173 VC firms and snowball interviews were also conducted in the Chinese state-owned and private-owned VCs as well as foreign VCs. Findings indicate foreign VC investors are more willing to build much denser relationships than those of Chinese state-owned and private VC firms in order to overcome the uncertainty. This result provides additional evidence that adopting close relationships or a guanxi-based (informal social network) strategy does not only depend on cultural issues such as East Asian culture, but also on high institutional uncertainty. Furthermore, this paper develops four propositions on how VC firms establish syndication influenced by high institutional uncertainty. Finally, the conclusion and discussion sections put forward implications to VC companies about how informal social networks facilitate the internationalization process and growth in foreign markets.

Entitled "Social networks and informal financial inclusion in China", and written by Shijun Chai, Yang Chen, Bihong Huang, and Dezhu Ye, the ninth and final article explores the heterogeneous impacts of social networks on informal financial inclusion for Chinese urban and rural households based upon the 2011 China Household Finance Survey (CHFS) database. This study has found that social networks can significantly increase the probability of households' participation in the informal financial market, augment the size of informal financial transaction, and raise the ratio of informal lending over the total household assets. This study has also identified the mechanisms through which the social networks affect households' participation in the informal financial market. By reducing information cost, perceived risk and precautionary saving, social networks play an even larger role for urban households than rural 
households. Notably, the effects of social networks on informal finance are strengthened with the development of formal financial market.

In sum, together in three sets, the nine articles jointly explain the phenomenon of informal network from multiple perspectives and under various conditions in the context of East Asia. Collectively, these nine articles first suggest that the informal ties and networks in the context of East Asia differ fundamentally from those in the context of the West, including different antecedents, mechanisms, and effects of informal ties and networks. Further, the nine articles also jointly show that there are meaningful distinctions between the major economies in East Asia. Finally, the nine articles as a whole imply that informal ties and networks tend to stay and persist over time in East Asia. More specifically, the nine articles in the Special Issue have effectively addressed the original research questions in our call for papers:

- What are the major similarities and distinctions between the informal social networks in East Asia in general, and China, Japan, and South Korea in particular?

- What are the similarities and distinctions between the informal social networks in East Asia and the concept of social capital as conceptualized in the West?

- Would informal social networks persist or disappear when formal institutions are more established in the later stages of societal development?

Next, we turn to the key implications of the nine articles for future research on informal ties and networks both in the East and the West, especially their interaction and integration as a major part of East-Meeting-West.

\section{The critical implications of the special issue}

\section{The theoretical implications}

In a reverse order of the above three research questions, the first major implication from the nine articles in this Special Issue is that informal ties and networks are unlikely to go away anytime soon in East Asia, and it is even possible for informal ties and networks in the West to regain some of their historical status so as to complement the imperfect roles of formal ties and formal institutions, especially in the emerging context of VUCA. This sheds light on the ongoing debate over if informal ties and networks will disappear after the solid establishment of formal institutions (Guthrie, 1998; Guthrie, 2002; Nee, 1992; Peng, 2003).

For instance, the meta-analysis study in this Special Issue (Wang, Tian \& Li, 2019) seems to suggest, in a highly counter-intuitive manner, that informal ties and networks tend to be more effective and more critical concerning competitive advantages in the context of the West where the informal institutions are looser (in contrast to the tighter informal institutions in the East) and individualistic value is stronger (in contrast to the stronger collectivistic value in the East). Further, this meta-analysis also shows that the network structural feature of centrality is more effective than that of structural hole (in contrast to network density or closure). One possible explanation is that, given the presence of well-established formal institutions, the role of informal ties and network as 
informal institutions is more complementary than in conflict for the purpose of seeking competitive advantages.

To lend further support for the argument about the persisting informal ties and networks, informal ties and networks still thrive in both Japan and South Korea despite their completely modern status as the advanced societies, as shown in the two conceptual studies by Horak and colleagues (Horak, Taube, Yang \& Restel, 2019; Yang \& Horak, 2019).

It is interesting to note that the empirical study by Hemmert (2019) concerning the different roles between interpersonal tie and inter-firm tie strength in the process of inter-firm collaboration for new product development (NPD) and university-industry research (UIR) bears the evidence that inter-firm tie strength is more effective than interpersonal tie for both interaction quality and performance outcome. However, we can provide some alternative explanations for this finding. First, it could be a possible bias in the measurement because interpersonal tie strength has not been directly measured, while inter-firm tie strength has been done so. Second, it is also possible that inter-firm tie strength could actually serve as the mediator between interpersonal tie and interaction quality or performance outcome. This is because that inter-firm tie strength is more directly associated with inter-firm collaboration than interpersonal tie or tie strength. Whichever explanation, the finding of the greater power on the part of inter-firm tie is not a denial or rejection of the persisting salience of informal ties and networks in South Korea.

All five articles concerning the Chinese guanxi bear the similar implications that informal ties and networks are expected to continue and persist in China at least for now. It is worth noting that the two empirical articles in the specific sector of financial service (Chai, Chen, Huang \& Ye, 2019; Luo, Rong, Yang, Guo \& Zou, 2019) seem to imply that the existence of informal ties and networks can be explained primarily as a rational response to the lack of certainty due to the absence of established formal institutions, such as mature financial markets for borrowing and lending as well as venture capital investment in China, we would rather offer a distinctive explanation that the need for informal ties and networks could be twofold with the competing logics of both informal (e.g., cultural preference) and formal (e.g., the rule of law and state policies) institutions, largely because both types of institutions provide the necessary legitimacy above and beyond the iron cage of formal institution as the biased, incomplete view (Dimaggio \& Powell, 1983; Scott, 2003). It seems that informal and formal institutions can be much more complementary than what had been recognized in the prevailing literature in the West (Chai et al., 2019; Horak \& Restel, 2016; Li, 2007b; Lin et al., 2016). The above view reflects the Chinese cognitive frame of yin-yang balancing, which will be discussed later.

A related secondary implication derives from the above primary implication is about the need for the unique role of informal ties and networks in the context of UVCA, especially in the unique role of informal ties and networks for the creation and exchange of tacit knowledge and personalized trust (Li, 2008, 2013). This argument casts a serious doubt about the linear advance from informal institutions to formal ones, as argued by North (1990) and also many other scholars (e.g., Guthrie, 1998; Guthrie, 2002; Nee, 1992; Peng, 2003). It is critical to note that the sufficient rationale (above and beyond the historical and cultural reasons) for the persistence of informal ties and networks even in the future is the special need for informal elements from the 
contextual reality in the post-modern era, which is characterized by VUCA. All articles in this Special Issue reflect this point, explicitly or implicit, especially the last seven articles (i.e., from the 3 rd to the 9 th articles).

It is interesting to note that the above answers to the third research question are suggestive of the answers to the second research question, which leads to the second major implication.

The second major implication from the nine articles in this Special Issue is that informal ties and networks in the context of East Asia tend to differ in certain fundamental ways from those in the context of the West. For instance, in the conceptual article after the above meta-analysis (Horak et al., 2019), the salient distinctions between the East and the West are compared, with the former focusing more on the stronger ties with the greater sentimental motives than instrumental ones in contrast to the latter focusing more the weaker ties with the greater instrumental motives than sentimental ones. The contrast between the East and the West has been further elaborated by the role of emotion in informal ties and networks in the study by Yang and Horak (2019). The comparative study on the different mentor-mentee relationships in the East and the West also lends support for this implication. Finally, the metaanalysis study (Wang et al., 2019) provides some implicit evidence in support of this implication. To various degrees, all articles in the Special Issue, explicitly or implicitly, support the above implication, especially the first five articles (i.e., from the 1 st to the 5 th articles).

A related secondary implication derives from the above primary implication is about the need for a balance between both similarities and distinctions between the East and the West concerning the formal and informal ties and networks as well as the both similarities and distinctions between different societies in the East Asia. In this sense, we need to recognize the salience of yin-yang balancing to frame paradoxical issues into dualities ( $\mathrm{Li}, 1998,2008,2012$ ), especially the three operating mechanisms, i.e., asymmetrical balancing, transitional balancing, and curvilinear balancing (Li, 2014, 2016; see Gao, Ren, \& Miao, 2018; Lin et al., 2015, for the initial empirical evidence). The need for the cognitive perspective of yin-yang balancing is reflected in the growing realization that complex management phenomena tend to be paradoxical in nature (Uzzi, 1997; see Schad, Lewis, \& Raisch, 2016 for the most recent review). In particular, the balance and interplay between opposite elements concerning informal ties and networks are salient for future research, including the balance and interplay between the East and the West; between formal and informal institutions; between ascribed and achieved bases; between substance (relational embeddedness) and structural dimensions (structural embeddedness); between strong and weak tie strengths; between instrumental and sentimental logics on the substance dimension; between density/closure and structural hole on the structural dimension; between bridging and bonding ties on the structural dimension; between centrality and peripheral on the structural dimension; between vertical/hierarchical and horizontal ties on the structural dimension, among others.

As for the first research question, it is critical to recognize that there are not only major differences between the East and the West, but also significant intra-regional distinctions between China, Japan and South Korea, especially with the last two as one group in contrast to China as somewhat exceptional in the East Asia. This is demonstrated in the article by Horak and colleagues (Horak et al., 2019). It is clear that Japan 
and South Korea share a number of informal characteristics, such as their emphasis on ascribed bases, strong ties, sentimental logic, and closed network structure, in contrast to the focus of Chinese informal ties and networks on a balance between both ascribed and achieved bases, both strong and weak ties, both instrumental and sentimental logics, and both open and closed network structures. In other words, there appear to be both fundamental similarities and distinctions between various types of informal ties and networks in East Asia as a region with many shared cultural traditions. This is especially true for those among China, Japan, and South Korea as the top three economies in this region.

If we emphasize the major similarities in the characteristics of informal ties and networks between the countries in the East Asia (with China, Japan and South Korea as the leading economies) as compared to those in the West, we can develop an Asian theory of informal social networks to complement and supplement the dominant theory of informal ties and networks as well as formal ties and networks (Li, 2007a, 2007b). This reflects the indigenous approach to research, which focuses on contextualizing research and developing indigenous constructs and models that are distinctive from the prevailing one in the West. However, if we focus on the key distinctions between the countries in the East Asia, we can develop at least two theories to best reflect the historical and cultural roots in the East Asia. For instance, we may develop one intraAsia theory of informal ties and networks for Japan and South Korea, while having another intra-Asia theory for China.

A related secondary implication derives from the above primary implication is about the need for a balance between both similarities and distinctions between different economies in the East Asia concerning the formal and informal ties and networks above and beyond those between the East and the West. Again, this is related to the Chinese perspective of yin-yang balancing (see $\mathrm{Li}, 2016$ for a review). However, we have to admit that the biggest weakness of this Special Issue is the lack of studies directly on Japan, and the next big weakness lies in the lack of comparative studies concerning the intra-region informal ties and networks, with the 2 nd article as the only exception.

In addition to the above three direct implications from the nine articles in this Special Issue, there are three derived indirect implications. First, there is an urgent need for a refined definition of informal ties and networks as explicit as possible, especially in the case of inter-firm ties and networks. The explicit definition is easy and direct for interpersonal ties and networks, but it is not the case for inter-firm ones. For instance, all four articles in the Special Issue concerning inter-firm ties and networks share the similar problem of only implicitly defining informal ties (i.e., the third article about the link between interpersonal tie and inter-organizational tie strength for research project collaborations in South Korea; the sixth article about various types of interorganizational ties, including political, business, and university ties, for innovation in China; the seventh article about the inter-firm ties to link and leverage for international expansion from China; the eighth article about the inter-firm ties among venture capital firms in their syndicated investment in China). Future research must pay special attention to the issue of how to conceptualize and operationalize informal ties and networks at the inter-firm level in contrast to those at the interpersonal level (see Currall \& Inkpen, 2002; Li, 2008; Li, Bai, \& Xi, 2012). In particular, future research must recognize and balance different mixes or interactions between interpersonal and inter- 
organizational ties as well as between cultural/historical forces and institutional/realistic forces (Luo et al., 2019).

Second, there is also an urgent need to focus more on the structural dimension. It is worth noting that all nine articles in the Special Issue focus primarily on the substance or content dimension of informal tie (i.e., the dimension of relational embeddeness), rather than the structural dimension of informal network (i.e., the dimension of structural embeddeness) (Granovetter, 1985; Gu, Luo, \& Liu, 2019; Uzzi, 1997). Future research should pay more attention to the relatively neglected dimension of network structure, including centrality, multiplexity, and density (closure or structural hole), among others (Burt, 1992; Coleman, 1990; Shipilov \& Li, 2012; Xiao \& Tsui, 2007; see Ahuja, Soda, \& Zaheer, 2012 for a review). For instance, a forthcoming review article on guanxi ( $\mathrm{Li}$ et al., 2019) highlights the need for a greater attention to the structural dimension of guanxi. For instance, it can be highly fruitful to compare the metaphor of cocoon for guanxi to provide pretection for network members with the metaphor of multi-color Chinese knot with multiple bases of ties to bond network members more tightly with each other (Du, Gao, \& Zhang, 2019; Li et al., 2019; cf. Burt, 2019; Zhao \& Burt, 2018).

Third and finally, there is an urgent need to focus on the interaction between the substance dimension for relational embeddeness and structural dimension for structural embeddedness (Granovetter, 1985; Gu et al., 2019). This is related to the urgent need to remedy the lack of focus on the process-related issue, especially the interaction between the substance dimension and structural dimension of informal ties and networks, which is often reflected in the interplay between bridging ties and bonding ties (see Halevy, Halali, \& Zlatev, 2019; Li et al., 2019, for the most recent reviews). For instance, it is interesting to study the process of evolution from a network as cocoon to that as multicolor Chinese knot.

Also related to the process-oriented shift in research focus, future research should pursue the cross-cultural geocentric approach by developing more integrative (Westmeeting-East) theories (e.g., Jukka, Blomqvist, Li \& Gan, 2017; Lin, Li, \& Roelfsema, 2018; Li, 2007b, 2008, 2016). However, we must remind that the indigenous approach remains necessary to develop relevant indigenous theories before anyone can even engage in cross-cultural geocentric approach for geocentric theories (e.g., Li, 1998; Li, 2007a; Li, 2014; Lin et al., 2015).

\section{The key practical implications}

All nine articles in this Special Issue have some practical implications for both Western and Eastern managers. First, for the Western managers, these studies help them understand the local practices and local perspectives concerning the informal ties and networks in the context of East Asia in contrast to those in the West. For the Eastern managers, these studies help them explicitly understand their own local practices and local perspectives, and the Eastern managers can be more proactive in leveraging their local informal ties and networks as well as more explicit in explaining the rationales behind their local practices to non-Asian managers, which is often necessary in the context of international business. This implication reflects the general fact that the informal ties and networks in East Asia differ fundamentally from those in the West, and there are also substantial intra-regional differences in East Asia. Second, both 
Eastern and Western managers should recognize the diverse types or forms of informal ties and networks, especially the major differences between interpersonal ties and interorganizational ties as well as between various types of organizations (such as business, state, and universities). Third, both Eastern and Western managers need to realize that the specific elements of informal ties and networks tend to be distinctive between East Asia and the West, such as the role of emotion or affect and the function of mentorship, especially the unique mix of instrumental and sentimental elements in East Asia. Fourth, both Eastern and Western managers need to realize that the structural issues are as salient as the relational issues, especially their interplay in a holistic and dynamic process of co-evolution. Finally, both Eastern and Western managers need to realize that paradoxical issues in management are not only unavoidable but also necessary and desirable, so they must learn how to effectively manage them, especially from the perspective of yin-yang balancing.

Acknowledgements We thank the following three colleagues for their support for this Special Issue:

Seok Choon Lew, Yonsei University (South Korea).

Yoshimichi Sato, Tohoku University (Japan).

Steven Lui, University of New South Wales (Australia).

Funding This study was financially supported by the National Science Foundation of China (NSFC71732007).

\section{References}

Ahuja, G., Soda, G., \& Zaheer, A. 2012. The genesis and dynamics of organizational networks. Organization science, 23(2): 434-448.

Begley, T. M., Khatri, N., \& Tsang, E. W. K. 2010. Networks and cronyism: A social exchange analysis. Asia Pacific Journal of Management, 27(2): 281-297.

Bstieler, L., \& Hemmert, M. 2008. Trust formation in Korean new product alliances: How important are preexisting social ties? Asia Pacific Journal of Management, 27(2): 299-319.

Burt, R. S. 1992. Structural holes: The social structure of competition. Cambridge, MA: Harvard University Press.

Burt, R. S. 2019. Network disadvantages entrepreneurs: Density, hierarchy, and success in China and the west. Entrepreneurship Theory and Practice, 43(1): 19-50.

Chai, S., Chen, Y., Huang, B. \& Ye, D. 2019. Social networks and informal financial inclusion in China. Asia Pacific Journal of Management (this issue).

Chen, C. C., Chen, X. P., \& Huang, S. 2013. Chinese Guanxi: An integrative review and new directions for future research. Management and Organization Review, 9(1): 167-207.

Coleman, J. S. 1990. Foundations of social theory. Cambridge, MA: Harvard University Press.

Currall, S. C., \& Inkpen, A. C. 2002. A multilevel approach to trust in joint ventures. Journal of International Business Studies, 33(3): 479-495.

DiMaggio, P. J., \& Powell, W. W. 1983. The iron cage revisited: Institutional isomorphism and collective rationality in organizational fields. American Sociological Review, 48(2): 147-160.

Du, M., Gao, H., \& Zhang, J. 2019. Toward a guanxi-bases view of structural holes in sales gatekeeping: A qualitative study of sales practices in China. Industrial Marketing Management, 76: 109-122.

Gao, H., Ren, M., \& Miao, Q. 2018. Toward a yin-yang balancing perspective of relational (guanxi) gatekeeping in international exchange relationships in China. Journal of International marketing, 26(2): $22-42$.

Gilbert, D. 2003. Strategic decision-making in Japanese trading companies: Case studies of information search activities. Journal of Management \& Organization, 9(1): 27-40. 
Granovetter, M. 1985. Economic action and social structure: The problem of embeddedness. American Journal of Sociology, 91(3): 481-510.

Gu, W., Luo, Y., \& Liu, J. 2019. Exploring small-world network with an elite-clique: Bringing embeddedness theory into the dynamic evolution of a venture capital network. Social Networks, 57: 70-81.

Guthrie, D. 1998. The declining significance of guanxi in China's economic transition. The China Quarterly, 154: $254-282$.

Guthrie, D. 2002. Information asymmetries and the problem of perception: The significance of structural position in accessing the importance of guanxi in China. In T. Gold, D. Guthrie, \& D. Wank (Eds.). Social connections in China: 37-56. New York: Cambridge University Press.

Halevy, N., Halali, E., \& Zlatev, J. J. 2019. Brokerage and brokering: An integrative review and organizing framework for third party influence. Academy of Management Annuals, 13(1): 215-239.

Hamaguchi, E. 1985. A contextual model of the Japanese: Toward a methodological innovation in Japan studies. Journal of Japanese Studies, 11(2): 289-321.

Hemmert, M. 2019. The relevance of interpersonal ties and inter-organizational tie strength for outcomes of research collaborations in South Korea. Asia Pacific Journal of Management (this issue).

Horak, S., \& Klein, A. 2016. Persistence of informal social networks in East Asia: Evidence from South Korea. Asia Pacific Journal of Management, 33(3): 673-694.

Horak, S., \& Restel, K. 2016. A dynamic typology of informal institutions: Learning from the case of guanxi. Management and Organization Review, 12(3): 525-546.

Horak, S., \& Taube, M. 2016. Same but different? Similarities and fundamental differences of informal social networks in China (guanxi) and Korea (yongo). Asia Pacific Journal of Management, 33(3): 595-616.

Horak, S., Taube, M., Yang, I. \& Restel, K. 2019. Two not of a kind: Social network theory and informal social networks in East Asia. Asia Pacific Journal of Management (this issue).

Jukka, M., Blomqvist, K., Li, P. P. \& Gan, C. 2017. Trust-distrust balance: trust ambivalence in Sino-Western B2B relationships. Cross Cultural \& Strategic Management, 24(3): 482-507.

Lee, J. 2000. Society in a vortex? Yonjul network and civil society in Korea. Korea Journal, 40(1): 366-391.

Lew, S.-C. 2013. The Korean economic development path: Confucian tradition, affective network. New York: Palgrave Macmillan.

Li, P. P. 1998. Towards a geocentric framework of organizational form: A holistic, dynamic and paradoxical approach. Organization Studies, 19(5): 829-861.

Li, P. P. 2007a. Guanxi as the Chinese norm for personalized social capital: Toward anintegrated duality framework of informal exchange. In H. W. Yeung (Ed.) Handbook of research on Asian business. London: Edward Elgar Publishing, Chapter 4, 62-83.

Li, P. P. 2007b. Social tie, social capital, and social behavior: Toward an integrative model of informal exchange. Asia Pacific Journal of Management, 24(2): 227-246.

Li, P. P. 2008. Toward a geocentric framework of trust: An application to organizational trust. Management and Organization Review, 4(3): 413-439.

Li, P. P. 2013. Entrepreneurship as a new context for trust research. Journal of Trust Research, 3(1): 1-10.

Li, P. P. 2014. The unique value of yin-Yang balancing: A critical response. Management and Organizational Review, 10(2): 321-332.

Li, P. P., Bai, Y., \& Xi, Y. 2012. The contextual antecedents of organizational trust: A multidimensional crosslevel analysis. Management and Organization Review, 8(2): 371-396.

Li, P. P., Zhou, S. S., Zhou, A. J., \& Yang, Z. 2019. Guan-Xi. Interacting toward a multi-color Chinese knot: Reconceptualizing and redirecting guanxi research. Management and Organization Review (forthcoming).

Lin, D., Lu, J., Li, P. P., \& Liu, X. 2015. Balancing formality and informality in business exchanges as a duality: A comparative case study of returnee and local entrepreneurs in China. Management and Organization Review, 11(2): 315-342.

Lin, L., Li, P. P., \& Roelfsema, H. 2018. The traditional Chinese philosophies in inter-cultural leadership: The case of Chinese expatriate managers in the Dutch context. Cross Cultural \& Strategic Management, 25(2): 299-336.

Luo, Y. D., Huang, Y., \& Wang, S. L. 2012. Guanxi and organizational performance: A meta-analysis. Management and Organization Review, 8(1): 139-172.

Luo, J-D., Rong, K., Yang, K., Guo, R. \& Zou, Y-Z. 2019. Syndication through social embeddedness: A comparison of foreign, private and state-owned venture capital (VC) firms. Asia Pacific Journal of Management (this issue).

Nee, V. 1992. Organizational dynamics of market transition: Hybrid forms, property rights. and mixed economy in China. Administrative Science Quarterly, 37(1): 1-27. 
North, D. 1990. Institutions, institutional change and economic performance. Cambridge, MA:Cambridge University Press.

Peng, M. W. 2003. Institutional transitions and strategic choices. Academy of Management Review, 28(2): 275-296.

Schad, J., Lewis, M.W., Raisch, S., \& Smith,W. K. 2016. Paradox research in management science: Looking back to move forward. Academy of Management Annals, 10: 5-64, 1.

Scott, W. R. 2003. Organizations: Rational, natural and open systems (5th edition). Eaglewood cliff, NJ. Prentice-Hall.

Shipilov, A. V., \& Li, S. X. 2012. The missing link: The effect of customers on the formation of relationships among producers in the multiplex triads. Organization Science, 23(2): 472-491.

Suzuki, N. 1989. The attributes of Japanese CEOs: Can they be trained? Journal of Management Development, 8(4): 5-11.

Uzzi, B. 1997. Social structure and competition in interfirm networks: The paradox of embeddedness. Administrative Science Quarterly, 42(1): 35-67.

Wang, H., Tian, L. \& Li, Y. 2019. A tale of two cultures: Social networks and competitive advantage. Asia Pacific Journal Management (this issue).

Xiao, Z., \& Tsui, A. S. 2007. When brokers may not work: The cultural contingency of social capital in Chinese high-tech firms. Administrative Science Quarterly, 52(1): 1-31.

Yang, I. 2006. Jeong exchange and collective leadership in Korean organizations. Asia Pacific Journal of Management, 23(3): 283-298.

Yang, M. M. 1994. Gifts, favors and banquets: The art of social relationships in China. Ithaca, NY:Cornell University Press.

Yang, I. \& Horak, S. 2019. Emotions, indigenous affective ties, and social network theory-The case of South Korea. Asia Pacific Journal of Management (this issue).

Yee, J. 2000. The social networks of Koreans. Korea Journal, 40(1): 325-352.

Zhao, C., \& Burt, R. 2018. A note on business survival and social network. Management and Organization Review, 14(1): 1-18.

Publisher's note Springer Nature remains neutral with regard to jurisdictional claims in published maps and institutional affiliations.

Dr. Peter Ping Li is Li Dak Sum Chair Professor of International Businessat the University of Nottingham atNingbo, China; Research Director, the Greater China Region of US-based Center for Creative Leadership(CCL), and also Professor of Chinese Business Studies at Copenhagen Business School, Denmark. Hewas former Professor of International Business at Xian Jiaotong-Liverpool University, China, and retiredProfessor of Management at California State University.

His primary research focus is on building geocentric (West-meeting-East) theories from the cultural andhistorical perspectives. He is regarded as the global thought leader in the two fastest growing areas: (1)indigenous management research, and (2) emerging multinational firms. He has published over 100 journalarticles, 20 book chapters, and 6 books. He serves on the editorial boards of 10 academic journals. He isthe founding Editor-in-Chief of Journal of Trust Researchas well as Senior Editor ofManagement andOrganization Reviewand also former Senior Editor of Asia Pacific Journal of Management.

Dr. En Xie is a Professor of Management at the School of Economics and Management, Tongji University,Shanghai City, China. His research interests include business strategy in emerging economies, strategicalliance networks, and international business. His research has been published in reputable academicjournals like Strategic Management Journal, Journal of Operations Management, Journal of WorldBusiness, International Business Review, and other leading management journals in China. He haspresented his works at AOM, AIB, CIMaR, and refereed management conferences in China. 